\title{
Evidence on the environmental impacts of farm land abandonment in high altitude/mountain regions: a systematic map
}

\author{
Neal R Haddaway ${ }^{1 *}$, David Styles ${ }^{2}$ and Andrew S Pullin ${ }^{1}$
}

\begin{abstract}
Background: Many ecosystems have developed in the presence of agriculture and cessation of management resulting from land abandonment can have significant ecological impacts. Around 56 percent of the utilised agricultural area of the European Union is classified as 'less-favourable areas' and much of this is mountainous. The small-scale and extensively managed farmlands that are common in mountain areas are particularly vulnerable to marginalisation and abandonment. We conducted the first systematic global mapping of evidence to inform stakeholders and policy makers of the potential impacts of farm land abandonment in mountain areas.

Methods: Evidence was collated from a range of academic literature databases and grey literature sources. Identified articles $(8,489)$ were screened for relevance at title, abstract and full text using predefined inclusion criteria set out in a published protocol. Relevant studies (165 across 189 articles) were then mapped using predefined coding and critically appraised for internal validity (i.e. susceptibility to bias).
\end{abstract}

Results: Mapping identified a number of interesting themes in the evidence base: the majority of research was undertaken in arable and mixed farming systems; large evidence bases were found in China, Spain and Italy; studies were mostly observational with spatial/successional comparators; biodiversity, soil and vegetation were most frequently studied. Several knowledge gaps were identified: including outcomes (socioeconomics and environmental hazards), regions (key mountain ranges including the Himalaya), and specific outcome-region groups (e.g. vegetation and soil measures in the UK). Several deficiencies in methodology were identified across studies: a lack of replication; non-random sample selection; lack of methodological detail (including details of spatial scale, replication, and sample selection).

Discussion: Systematic mapping has produced a searchable database of studies relating to high altitude farmland abandonment. The map identifies a number of potential areas for fruitful future synthesis, for example research on biodiversity, soil and vegetation in the Loess Hilly Plateau in China, and soil research in Spain. Such synthesis would be rapid given the effort expended here in identifying and screening relevant articles. It also points to several areas that were under-represented in the literature, such as natural hazards (avalanche, fire and flood risk), that would potentially benefit from increased primary research.

Keywords: Agriculture, Abandonment, Mountains, Alpine, Remote, Farming, Environmental impacts

\footnotetext{
*Correspondence: neal_haddaway@hotmail.com

${ }^{1}$ Centre for Evidence-Based Conservation, School of the Environment and Natural Resources and Geography, Bangor University, Bangor LL57 2UW, UK Full list of author information is available at the end of the article
} 


\section{Background}

Farm land abandonment can be simply defined as the cessation of agricultural activities on a given surface of land, yet there is no common precise definition of agricultural farmland abandonment in the literature [1]. Farm land abandonment occurs when income or resource generation cease to be viable or sustainable and the possibilities of adapting via changes in farming practices have been expended [2]. According to a study by Ramankutty and Foley [3], global abandonment of croplands has occurred over an estimated 1.47 million $\mathrm{km}^{2}$ between 1700 and 1992. Meanwhile, Pointereau et al. [1] estimate that 9.09 Mha of agricultural land have been abandoned across 20 European countries between 1990 and 2000. Data cited for France for the period 1992 and 2003 show that grassland represented $57 \%$ of abandoned agricultural land; cropland $30 \%$ and vineyards and hedges/groves each $6 \%$. However, the lack of a standardised definition of abandoned agricultural land, and the difficulty of matching this to available datasets, means that accurate estimates of abandoned area are lacking.

Land abandonment has a number of well-studied drivers, including environmental (e.g. reductions in soil fertility), economic (e.g. market globalisation) and socio-political (e.g. rural depopulation) causes [4]. From a socio-economic perspective, the abandonment of agricultural land is typically regarded as detrimental, owing to the implied loss of employment and income in rural areas. From an environmental perspective, the impacts of abandonment may be viewed as either an opportunity for ecological restoration to a state prior to agricultural establishment (typically regarded as beneficial), or as the loss of an ongoing process of land management and an associated threat to biodiversity (typically regarded as detrimental). Whether land abandonment poses an ecological opportunity or threat depends upon the agricultural history and the presence of systems that depend upon regular management for their existence. In Europe, many ecosystems have developed in the presence of agriculture and the loss of continued management resulting from land abandonment can have significant negative ecological impacts [4]. Pointereau et al. [1] suggest that abandonment of intensive agriculture often results in ecological benefits for the affected parcel of land, whilst abandonment of low intensity agricultural is more likely to result in a negative ecological impact owing to the role of such agriculture in maintaining systems classified as "high nature value" (HNV).

Around 56 percent of utilised agricultural area (UAA) of the European Union (EU) is classified as 'less-favourable areas' by the Common Agricultural Policy (CAP). According to MacDonald et al. [2], much of this is mountainous, and a report in 2004 identified mountainous regions as constituting 39.9 percent of the area of the 15 Member States at the time [5]. Mountain areas, however, are difficult to define. For the purposes of examining farm land abandonment, mountainous areas are defined by their unfavourable topography, remoteness and extreme climate. Mountainous areas are typically described by elevation and/or slope, but this can vary significantly between countries. For example, Austria defines mountain areas as being above $700 \mathrm{~m}$ or above $500 \mathrm{~m}$ if slope is greater than 20 percent, whilst Spain more strictly defines them as being above $1000 \mathrm{~m}$, over 20 percent slope and a $400 \mathrm{~m}$ elevation gain relative to surrounding land. Some definitions include low altitude areas where low mean temperatures and alpine vegetation reflect those in the high altitude Alps, such as Sweden and Finland. Other definitions use ruggedness assessed from satellite imagery e.g. [6].

The small-scale and extensively managed farmlands that are common in mountain areas are particularly vulnerable to marginalisation and abandonment [7]. A report from the Cross-Compliance Network identified mountainous areas as key areas likely to experience farmland abandonment [8]. The causes of farmland abandonment in mountainous areas are expanded upon in more detail in Pointereau et al. [1] to include; steep slope, distance from the farm to the field, low accessibility, poor soils, land used as alpine pastures, small farms, high cultivation costs and low field size.

Resilience and adaptability in farming systems in mountain regions is limited for a number of reasons, including remoteness, climate and physical constraints, and the aversion to risk-taking, traditional cultural values and limited skill sets often held by the local population [2]. Limitations to the adaptability of agriculture in mountain regions have been compounded by the historical paucity of agricultural research in these areas and a bias towards lowland regions e.g. [9].

Consensus in the literature about the impacts of farmland abandonment in mountain regions is generally lacking. A limited review of CAB Abstracts focusing on land abandonment was published in 2007 [10]. A systematic review is currently underway on the subject of land abandonment in the Mediterranean [11]. A conceptual review of several case studies of land abandonment and EU policies responding to the problem for mountain areas was published in 2000 [2]. Systematic mapping was chosen as a suitable method for collating and cataloguing evidence of the impacts of land abandonment because the subject has not been synthesised, and the state of the evidence base was unknown. A systematic map of evidence on high altitude farmland abandonment was chosen as part of a wider project investigating best practice in agriculture as a demonstration of the suitability of the method for mapping documented knowledge. Systematic mapping appropriately identifies knowledge gaps and potential systematically reviewable questions; key benefits in this subject area. This systematic map is also intended as a demonstration of the 
suitability of the method for agricultural research synthesis in informing policy-making. The work herein forms the first systematic mapping of the evidence of impacts of farm land abandonment in mountain areas across the globe.

\section{Objective of the review Primary question}

The primary question of this systematic map is;

What evidence exists on the environmental impacts of farm land abandonment in mountain regions?

This review is in the form of a systematic map, cataloguing the existing evidence across a wide range of variables such as setting, methodology, scale, measured outcomes etc. Mapping was undertaken to full text, meaning that the full text articles of all relevant abstracts were assessed and relevant full texts coded based on the information in these full text documents. The primary output and key objective of the systematic mapping process is an interrogatable database of research into the socioeconomic and environmental impacts of high altitude/ mountainous regions.

The question has the following components:

Population: All mountainous agricultural lands (global scope).

Exposure: Abandonment of agricultural land management. This definition is in accordance with that of Coppola [12] and Pointereau et al. [1] and specifies the cessation of all agricultural activity.

Comparator: Before-after land abandonment (temporal comparator), or un-abandoned nearby surrogate (spatial comparator).

Outcome: All outcomes relating to environmental and socio-economic impacts, including but not restricted to; natural hazards (fire-/flood risk, land/mud slides), soil (fertility, erosion), water (chemistry, eutrophication, sediment load, hydrology), ecosystem functioning (biodiversity, abundance, invasive species presence), human health and wellbeing (including income, employment, attitude).

\section{Methods}

The final methodology for the systematic map reported herein differs in several ways from the published protocol [13]. The title has been modified because it more accurately reflects the objective of the mapping exercise. Due to the relatively high exclusion of full texts following screening at abstract level it was decided not to generate a map based on abstracts only in addition to the full text map, since its accuracy would be questionable. Minor changes to the coding occurred due to the iterative nature of the coding and full text assessment process. Finally, rather than assign critical appraisal categories to each study it was decided to use a basic scoring system for the purposes of assessing the collective susceptibility to bias of subsections of the evidence rather than individual studies.

\section{Search strategy \\ Search terms}

Scoping was undertaken in order to identify suitable relevant key terms to be included in the finalised search string (see Additional file 1). These terms include aspects of the exposure (farm land abandonment) and the population (high altitude/mountain regions) and the finalised search string is displayed in Table 1. Outcome terms were not included in the string because of the number of returns based only on exposure and population terms, which was deemed to be manageable. Furthermore, the aim of the map is to document the available literature, including the variety of forms of outcomes measured in the evidence base. Outcome documentation was therefore an iterative process, and all relevant outcomes were coded.

Search terms were only established in English language. The major academic databases detailed below catalogue non-English language research by translating titles, abstracts and keywords into English. There is a risk that this may introduce bias, but the call for evidence submitted to the identified author list and via social media (see below) should act as to include some non-English evidence if it was available. The inclusion of non-English language academic databases was outside the scope of this review, but would be a worthwhile addition during any update.

\section{Databases}

The search aimed to include the following online databases which cover the breadth and depth of available literature on the topic:

1) ISI Web of Knowledge (inc. ISI Web of Science and ISI Proceedings)

2) Science Direct

3) Directory of Open Access Journals

4) Copac

5) Agricola

6) $\mathrm{CAB}$ Abstracts

7) CSA Illumina/Proquest

8) GreenFile

Where databases did not accept the full search strings detailed in Table 1, search strings were modified according to the database help files, sometimes based on only pairs of exposure terms to be as sensitive as possible. All database searches and outcomes are recorded in Additional file 1.

\section{Search engines}

The following internet search engines were used to identify relevant grey literature. The first 150 hits from each 
Table 1 Finalised search string following scoping in Web of Knowledge

\begin{tabular}{|c|c|c|}
\hline & Search string & $\begin{array}{l}\text { WoK } \\
\text { hits }\end{array}$ \\
\hline \multirow[t]{2}{*}{ Exposure terms } & ((grassland OR farm* OR cropland OR agriculture* OR land OR *field OR pasture) AND (destock* OR abandon*)) & 26,351 \\
\hline & AND & \\
\hline Population terms & $\begin{array}{l}\text { ("high altitude" OR "higher altitude" OR "high ground" OR "higher ground" OR *alpine OR montane OR mount* OR elevat* } \\
\text { OR highland OR hill* OR upland OR plateau OR mesa OR tableland OR slope OR aspect OR remote* OR massif OR sierra } \\
\text { OR steep OR rugged OR apennine OR alps OR volcano* OR Carpathian* OR Pyren* OR Caucasus OR Andes OR Rockies) }\end{array}$ & 7,213 \\
\hline
\end{tabular}

*denotes wildcard function that includes all possible word endings.

engine were screened (based on sorting by relevance of results where possible). Where abstracts were lacking articles were included to the full text assessment stage.

Google Scholar http://scholar.google.co.uk/.

Scirus http://www.scirus.com/.

Dogpile http://www.dogpile.co.uk/.

All search engine searches and outcomes are recorded in Additional file 2.

\section{Specialist sources}

The following specialist organisations were searched for relevant grey literature using manual searches of their websites and automatic search facilities using key terms (such as abandon*).

Alterra http://www.wageningenur.nl/en/Expertise-Services/ Research-Institutes/alterra.htm.

Centre for Ecology and Hydrology http://www.ceh.ac.uk/. National Farmers Union http://www.nfuonline.com/ home/.

Global Environment Centre http://www.gec.org.my/.

Greenpeace http://www.greenpeace.org.uk/.

Joint Nature Conservation Committee http://jncc.defra. gov.uk/.

Macaulay Land Use Research Institute http://www. macaulay.ac.uk/.

National Soil Resources Institute http://www.cranfield. ac.uk/sas/nsri/.

Natural England http://www.naturalengland.org.uk/.

Royal Society for the Protection of Birds http://www. rspb.org.uk/.

Society for Ecological Restoration http://www.ser.org/.

DEFRA http://www.defra.gov.uk/.

Environment Agency http://www.environment-agency. gov.uk/.

PBL Netherlands http://www.pbl.nl/en/.

German Federal Ministry of Agriculture http://www. bmelv.de/EN/.

Thunen Institute http://www.ti.bund.de/en/.

ETH Zurich http://www.ethz.ch/index_EN.

European Environment Agency http://www.eea.europa. $\mathrm{eu} /$.

EC Ag and Rural Dev site http://ec.europa.eu/agriculture/. IEEP http://www.ieep.eu/.
JRC Institute for Env Sustainability http://ies.jrc.ec. europa.eu/.

JRC Institute for Prospective Tech Studies http://ipts. jrc.ec.europa.eu/.

United Nations Environment Programme http://www. unep.org/.

Food and Agriculture Organisation http://www.fao.org/ index_en.htm.

Convention on Biological Diversity http://www.cbd.int/ convention/.

World Wildlife Fund http://www.wwf.org.uk.

Associations des Populations des Montagnes du Monde http://www.mountainpeople.org.

Mountain Partnership http://www.mountainpartnership. org.

The International Centre for Integrated Mountain Development http://www.icimod.org.

Where organisational website search facilities did not accept the full search strings detailed in Table 1, search strings were modified according to the search help files (where provided), or subsets of key terms were searched individually. All organisational website searches and outcomes are recorded in Additional file 3.

\section{Search comprehensiveness assessment}

The comprehensiveness of the above search strategies was assessed in a number of ways. Firstly, key bibliographies from relevant reviews were compared to the search results to check that all relevant articles have been identified through searches. These bibliographic testing strategies are detailed in Additional file 4. Secondly, search results were compared with a list of includable studies, identified by subject experts prior to the review. This key article testing is described in the database search strategy in Additional file 1 .

\section{Article retrieval}

Full texts were obtained digitally where possible (as PDF/ Microsoft Word files), using Bangor University subscriptions if necessary. Where sources were not available through Bangor University, authors were contacted directly via email for copies of their articles. Resources that 
were unavailable digitally were obtained physically and scanned in (in accordance with copyright law).

\section{Author contact}

Authors and research-related stakeholders were contacted with a request for the submission of relevant evidence in a number of ways. Firstly, when authors of inaccessible articles identified through the above searches were contacted requesting unobtainable articles they were also asked to submit evidence that may not be catalogued by academic databases, particularly grey literature and non-English language articles. Secondly, calls for submission of evidence were made using the social networking web sites Linked In, Research Gate and Academia. edu. Finally, once the map database had been populated, all author email addresses extracted from full texts were contacted with a further request for the submission of relevant evidence that may have been missed by the methodology detailed in the published protocol. Evidence submitted at this time, once the map was already complete, could not be screened, coded and included in the map, but a list of potentially relevant studies submitted through this call for evidence is included in Additional file 5 as a basis for future updating of the map.

\section{Study inclusion criteria}

Study selection, according to the predefined inclusion criteria detailed below, proceeded in a three stage, hierarchical process: titles, abstracts and finally full texts were assessed against the inclusion criteria. Any doubt over the presence of a relevant inclusion criterion (or if information is absent) resulted in the articles being retained for assessment at a later stage. Title- and abstract-level assessment did not assess the presence of a comparator, which is typically not explicit. Since titles and abstracts in grey literature often do not conform to scientific standards, assessment proceeded immediately to full text assessment. Consistency checks were undertaken using a subset of 100 abstracts by two reviewers (NH and $\mathrm{AP}$ ) independently of one another. Screening decisions were then compared using a Kappa test of agreement [14]. A score of 0.613 was obtained, which indicates substantial agreement. The few cases of disagreement were discussed and understanding of the inclusion criteria was improved before screening of the remaining abstracts.

The following aspects of the systematic review question formed inclusion criteria when assessing potentially relevant literature:

Relevant population(s): Any high altitude or mountainous region, any region with restricted access due to ruggedness, any region with possible agricultural difficulties or limits on agricultural advancement or adaptability as a result of slope, altitude, topography or ruggedness [global scope]

Types of exposure/intervention: Abandonment of agricultural land or reinstating of agricultural activity in agricultural land following abandonment

Types of comparator: Before land abandonment and/or an un-abandoned control site, or a relevant successional gradient representing change following abandonment (i.e. recent abandonment)

Types of outcome: All environmental and socioeconomic outcomes, including but not restricted to; soil chemistry (including carbon and GHG flux), soil erosion, water chemistry, hydrology, natural hazards, biological diversity and abundance, presence of invasive species, human health and wellbeing

Types of study: Both observational and experimental field studies. Experimental field studies (i.e. simulated abandonment) must investigate continued

abandonment over a period in excess of one year

Unobtainable and untranslatable studies are listed in Additional file 6. Excluded studies are listed along with reasons for exclusion in Additional file 7.

\section{Map coding}

Coding of studies was undertaken based on full texts using key words and expanded comments fields describing various aspects of study design and setting. Key variables of interest were identified through scoping activities and discussion with subject experts. Coding options within these key variables were then compiled in a partly iterative process, expanding the range of options as they were encountered during scoping. The finalised coding tool for the map is displayed in Additional file 8 .

Individual lines within the database represent a unit of one study-article, i.e. each individual reporting of a study. Multiple studies reported within one article are entered as independent lines in the database. Separate articles that report different outcomes from one study are entered as separate lines. This is to reflect the possible differences in reporting between different articles on the same study. These linked articles are highlighted as such, however, and are treated as one study unit.

\section{Critical appraisal of study internal validity}

Coding was used to describe the internal validity (IV) of each included study. Each study was given a score for each of the five variables listed A-E below. Studies therefore have a possible score of between 0 and 10. External validity was not taken into account since this is a systematic map and does not relate to any one context. Care was taken to avoid double scoring of individual failings, such as a lack of replication or low methodological detail. A subset $(10 \%)$ of studies was scored by an additional 
reviewer and disagreements were resolved through discussion and clarification. A breakdown of the scoring by the following variables is displayed in the systematic map database in Additional file 9.

\section{A. Replication}

Studies were assessed for their degree of true replication. True replication exists only at the level at which the intervention is administered/the exposure experienced. Pseudoreplication was inadmissible in this scoring. Sample size refers to the smallest sample (whether in comparator or intervention). Successional gradients count as 1 group.

a. Well-replicated ( $>10$ samples per group) 2

b. Moderate level of replication (4-10 samples per group) 1

c. Poorly-replicated/not stated (1-3 samples per group) 0

\section{B. Sample selection}

Study sample selection methods were assessed. Any form of randomised selection procedure scored highly, as did studies that deliberately spread samples evenly across clear potential confounders. Implied random or blocked designs received an intermediate score. Stated purposive selection or those that are clearly purposive (i.e. where no replication) failed to score.
a. Random/blocked/exhaustive 2
b. Not stated but possibly random/blocked 1
c. Purposive/not stated 0

\section{Level of methodological detail}

Articles' level of methodological detail was assessed. Well documented studies scored highly. Those with some missing information received an intermediate score. Those with very limited methodology failed to score. Understandability of text and grammar/ spelling were not taken into account.
a. High 2
b. Moderate 1
c. Low 0

\section{Other sources of potential bias}

Sources of potential bias that do not include a lack of replication or sample selection (to avoid double scoring) were assessed. Potential confounders include; clear differences in environmental conditions, substantial spatial separation between intervention and control sites, or the presence of other variables that may confound the impact of the intervention/exposure.
a. None evident 2
b. Potential confounder 1
c. Clear confounder 0

\section{E. Study design}

Studies were assessed for the form of the comparator. If both before/after and intervention/comparator are available (BACI; before-after-control-impacts) the study scored highly. Studies with one comparator received an intermediate score. Studies with successional gradient comparators that lack a baseline failed to score.
a. BACI 2
b. Modelled 1
c. Temporal (before/after) 1
d. Spatial (intervention site/control site) 1
e. Successional gradient (no baseline)/not stated 0

\section{Systematic map database}

The systematic map output is in the form of a database of studies that describes the nature and location of evidence on the review topic. The database is provided in Additional file 10: Table S1. This database is easily searchable and freely accessible. A help file to assist readers with interrogation of the map is provided in the Appendix. The map may form the basis for further primary research by identifying key knowledge gaps, and may also form the basis for further secondary research as a starting point for the synthesis of information in focused systematic reviews.

\section{Results}

Evidence identification, retrieval and screening

A schematic showing the processes involved in this systematic map and numbers of articles and studies moving between stages in shown in Figure 1.

Searches of academic literature databases, undertaken between $7^{\text {th }}$ and $13^{\text {th }}$ May 2013 (detailed in Additional file 1), identified 9,355 potentially relevant articles. Web search engines added an additional 498 articles (see Additional file 2). Identification of duplicates removed 1,455 references. Screening of these results at title and abstract yielded 1,473 and 650 relevant articles, respectively. Other sources of information (bibliographic checking, web search engines, organisational websites, secondary sources and author submissions; see Additional files 3 and 4) contributed an additional 91 articles; 741 potentially relevant full texts in total. A total of 215 articles could not be obtained in full text and 26 articles were not included in further stages due to complications with translation (see Additional file 6). Table 2 details the main reasons for article inaccessibility, citing the numbers of articles in each category. 


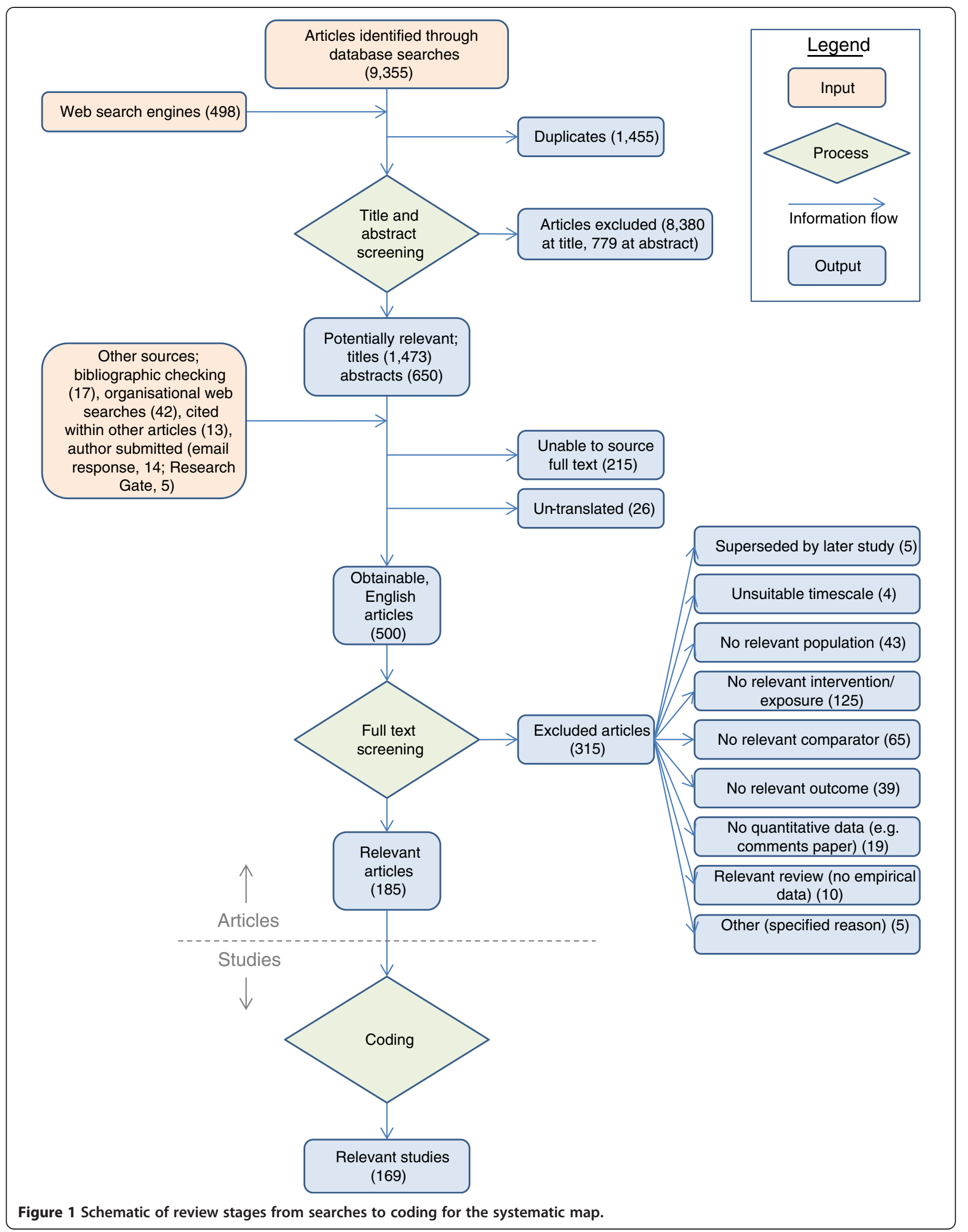


A total of 500 articles were obtained in full text (67\% retrieval rate). A total of 59 contact email addresses for authors of articles that were not obtainable were contacted with a request for full texts: 21 requests were successful, 1 referred to a conference presentation, 1 was not available electronically, and 35 email addresses failed (receiving bounces/fail alerts). This retrieval rate is low for systematic reviews. We attribute this to the large proportion of research published in Chinese journals that have specific access restrictions. This low retrieval rate may, therefore, reduce the utility of the map with respect to Chinese research, but much of this research was published in Chinese, reducing its usability in this review if it were to have been obtained.

Of the 500 obtained articles, 315 were excluded (see Additional file 7). Reasons for exclusion were: article was superseded by a later article; study was undertaken over an unsuitable timescale (i.e. intervention was enacted for less than one year); lack of relevant population (i.e. non mountainous); lack of relevant intervention/exposure (including incomplete abandonment); lack of relevant comparator; lack of relevant outcome (e.g. land use change documented alone); no quantitative data (e.g. comments paper); relevant review (no empirical data); other specific reasons.

In total, 185 articles were coded for the systematic map database, corresponding to 169 individual studies.

Articles came from a range of time periods, with more publications on the subject in recent years (Figure 2). Thirteen articles included in the map were in non-English language, with the majority of these (10) being in Chinese. The earliest included publication was from 1964, with the number of articles increasing over time in an exponential manner.

Population descriptors used by articles included in the systematic map are displayed in Figure 3. The most common descriptors were 'alp"', 'hill"', 'mount"' and 'plateau'. Seven articles were identified by searching of other resources (i.e. not academic databases). These seven articles did not use a population descriptor in the title, abstract or keywords, but the studies within them

Table 2 Unobtainable articles at full text with description of access restriction

\begin{tabular}{lc}
\hline Description of access restriction & $\begin{array}{c}\text { Number of } \\
\text { articles }\end{array}$ \\
\hline No institutional subscription & 134 \\
Unpublished conference proceedings/oral presentation & 11 \\
Citation only, no indication of holdings/online access & 70 \\
\hline
\end{tabular}

were included according to the application of the inclusion criteria in spite of this.

Critical appraisal identified a large number of studies that undertook no or little replication (Figure 4). Very few studies employed randomisation or exhaustive sampling. In general, methodological detail was limited, with $60 \%$ of studies given a '0' rating in this critical appraisal category. Studies scored highly in general for confounding factors, since methodological details were typically low and identifying potential confounders was, as a result, rarely possible. Studies typically scored moderately well for study design: few studies had strong forms of design (i.e. BACI), with most using a single comparator. A subset of 37 studies examined successional gradients following abandonment with no baseline.

\section{Systematic map findings}

Studies identified in this systematic map were undertaken across 35 countries (Figures 5 and 6). China was the most studied country (41 studies), followed by Spain (24), Italy (19), France (12) and Switzerland (11).

The altitude of study sites differed substantially between countries (Figure 7), as do the definitions of the term 'mountain' see [13]. Eighteen of the 34 countries whose studies reported altitude were from above 1,000 metres above sea level (m.a.s.l.), with an average altitude for the 127 studies from 18 countries of 1,764 m.a.s.l. The remaining studies had an average study height of 592 m.a.s.l.

There was a fairly even mixture of studies on arable abandonment and pasture abandonment, with a smaller subset of studies examining abandonment of mowing (Figure 8). A large number of studies failed to state the farming system (27 studies). Arable was the predominant farming system in China, Spain and Italy (Figure 6).

The majority of studies in the map were observational, with the remainder being predominantly experimental and some modelled studies (Figure 9a). A number of studies (13) employed BACI formats (both temporal and spatial comparators), but the majority used either spatial comparators (i.e. before and after) or successional gradients (i.e. several time periods following abandonment) (Figure 9b).

Figure 10 displays studies' time since abandonment, separated by observational, experimental and other study designs. Observational studies cover a fairly consistent range of abandonment periods, although 31-40 years appears to be underrepresented. A large number of studies failed to report abandonment period (25 studies). Experimental studies were most frequently carried out in recently abandoned farmland (1-10 years), and no experimental studies above the 31-40 year abandonment category were found. 


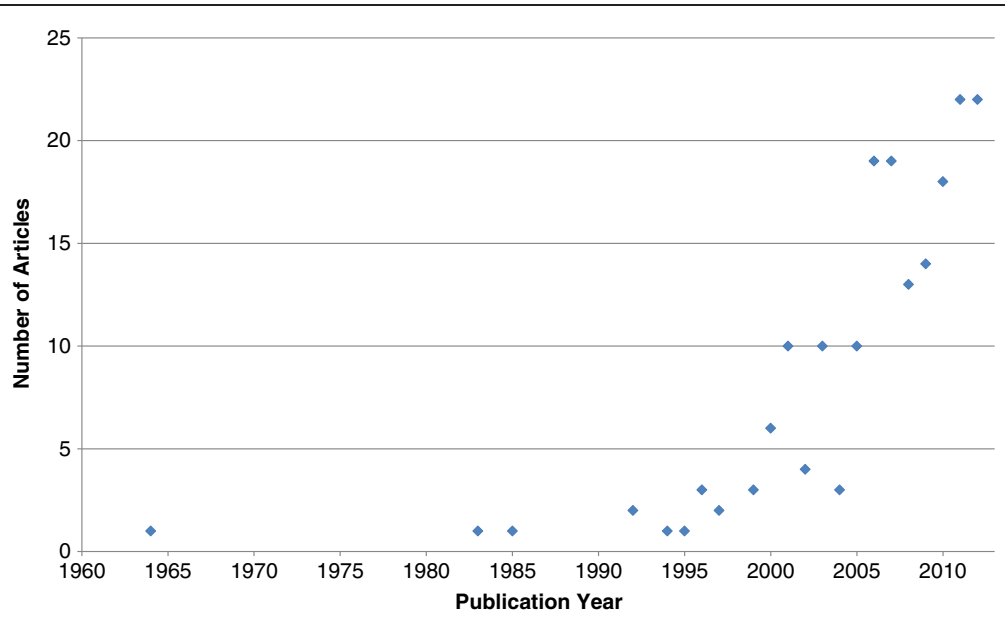

Figure 2 Publication year of articles included in the systematic map.

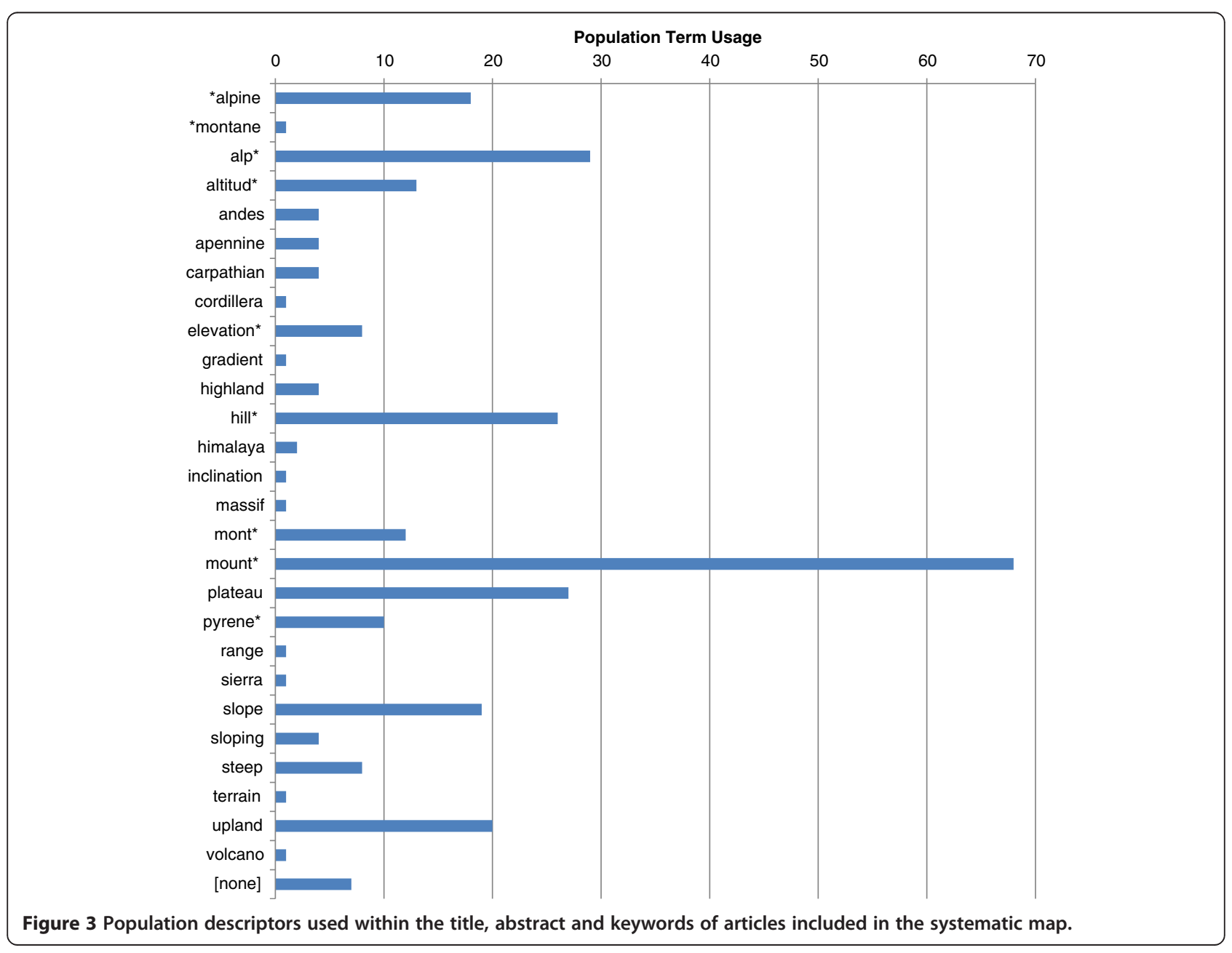




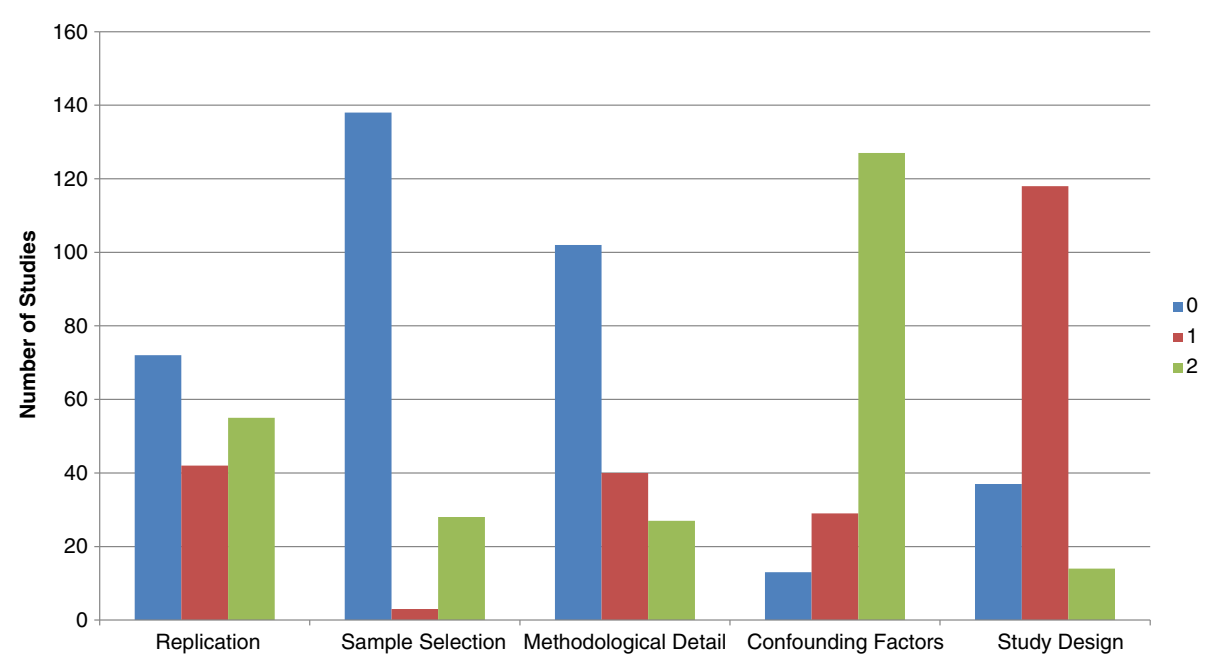

Figure 4 Number of studies across critical appraisal scores for five assessment categories (see Methods for details). 0 represents a poor quality score, whilst 2 represents a high quality score.

The most frequently studied outcomes were biodiversity, soil and vegetation (Figure 11a). Vegetation outcomes predominantly related to all vascular plants, with some named vegetation subgroups (lichen, moss, roots, shrubs and grasses and trees) also reported (Figure 11b) and included such measures as tree density, standing crop, and shoot dry mass. Soil outcomes were predominantly soil chemistry (e.g. pH, solute concentration, elemental concentration), and soil structure (e.g. bulk density, porosity, sand/silt/clay composition) (Figure 11c). Biodiversity

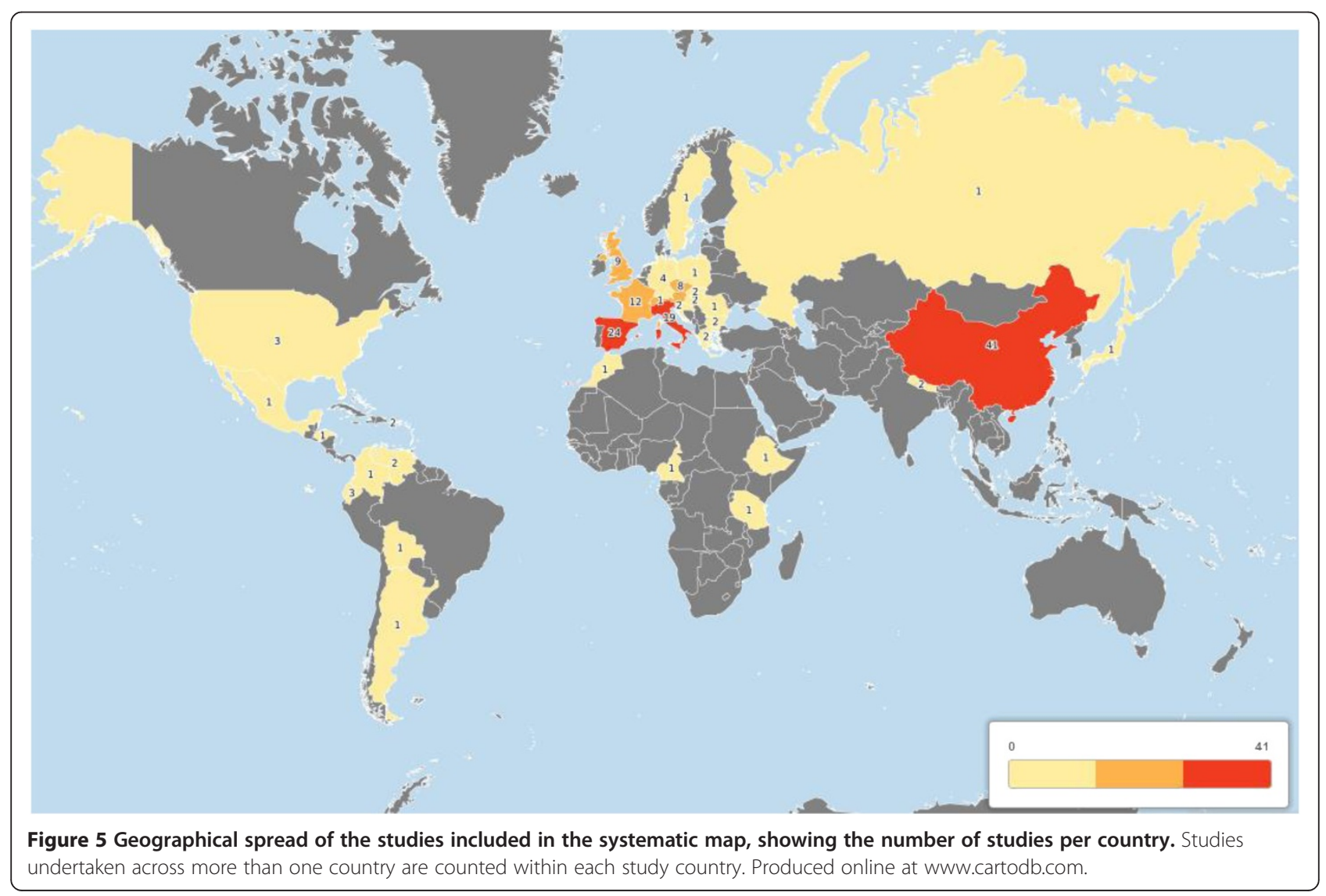




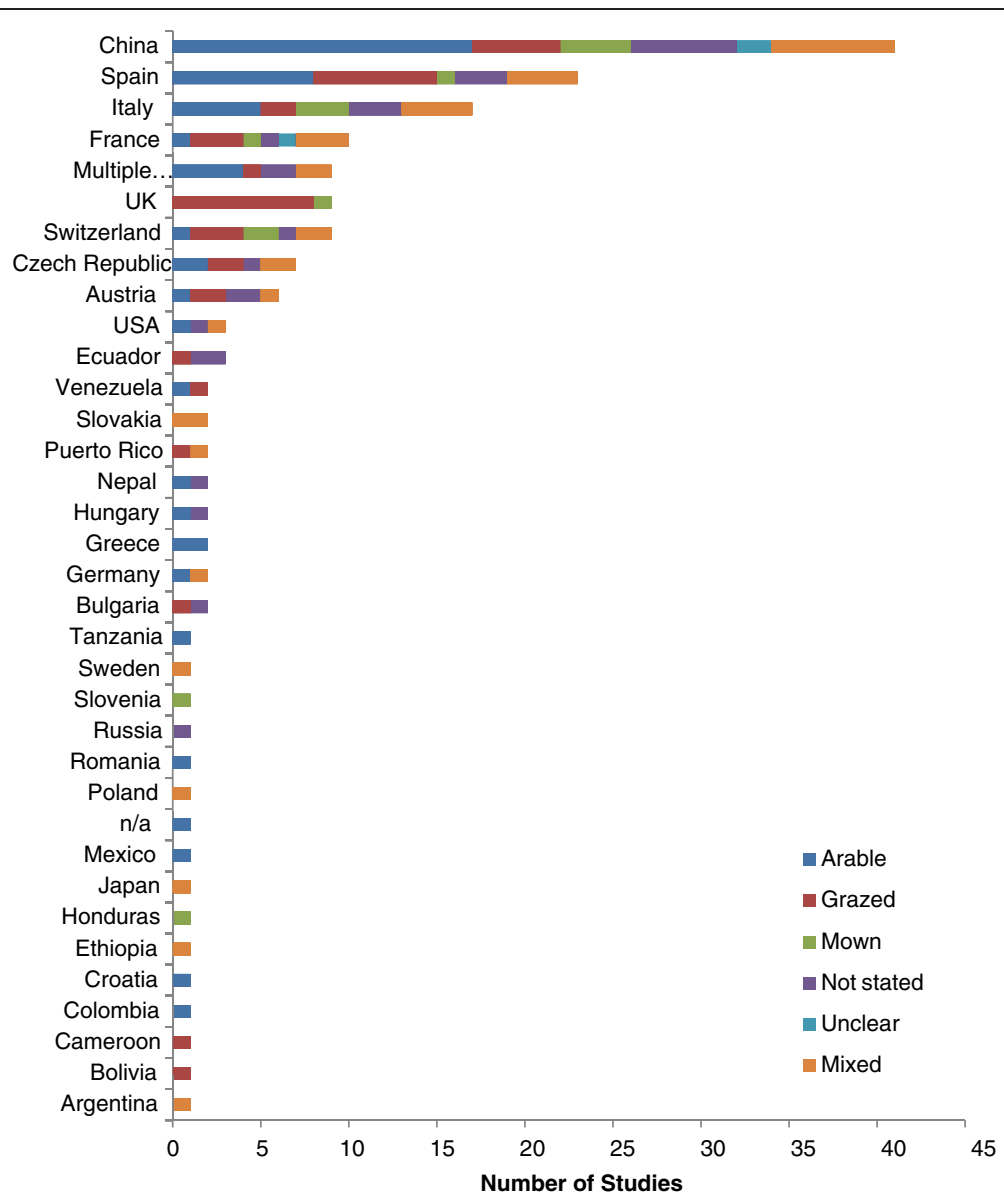

Figure 6 Number of studies performed in different countries separated by farming system. Studies undertaken across more than one country are counted within each country.

outcomes were overwhelmingly measures of vascular plant diversity, including diversity indices, abundance, richness, and evenness.

Additional file 10: Tables S1 and Additional file 11: Table S2 display the systematic map across outcomes and countries enabling an assessment of which bodies of combinable evidence are sufficient to allow synthesis and which areas may represent knowledge gaps. Additional file 10: Table S1 shows the number of studies in each country for the 12 major outcome groups and Additional file 11: Table S2 displays the total critical appraisal score for each of these cells. By highlighting the cells with a high volume and high combined quality of evidence it is apparent that the evidence base in China is substantial, covering a large body of studies on biodiversity, soil and vegetation outcomes, and this evidence has a high total CA score. In general the evidence across Europe is relatively strong (a relatively high total CA score), both in terms of the numbers of studied outcomes and the strength of the evidence. Additional file 12: Table S3 details the mean critical appraisal score, and identifies countries and outcome groups that have evidence that is in general of particularly high standard. This table demonstrates that, typically, single studies of low susceptibility to bias are present in the evidence base, but that groups of studies that are consistently low susceptibility to bias are not present. Thirty-two of the 91 outcome groups/countries combinations identified by the map were of a mean critical appraisal score of 5 or above.

Key knowledge gaps can be seen across all countries for socioeconomic outcomes (including employment, farming, human attitude) and outcomes relating to environmental hazards (including snow and water). Regions other than Europe and China are underrepresented, with evidence from key mountain ranges missing; for example the Rockies, the Andes, the Caucasus, the Himalaya, the Karakoram, the Great Dividing Range and the Urals.

The subjects above, although gaps, are not necessarily worthy of filling by novel primary research. Some of these gaps are surprising, for example environmental hazards, since avalanche, land slip and flood risk should be particular concerns in mountainous regions. The particular 


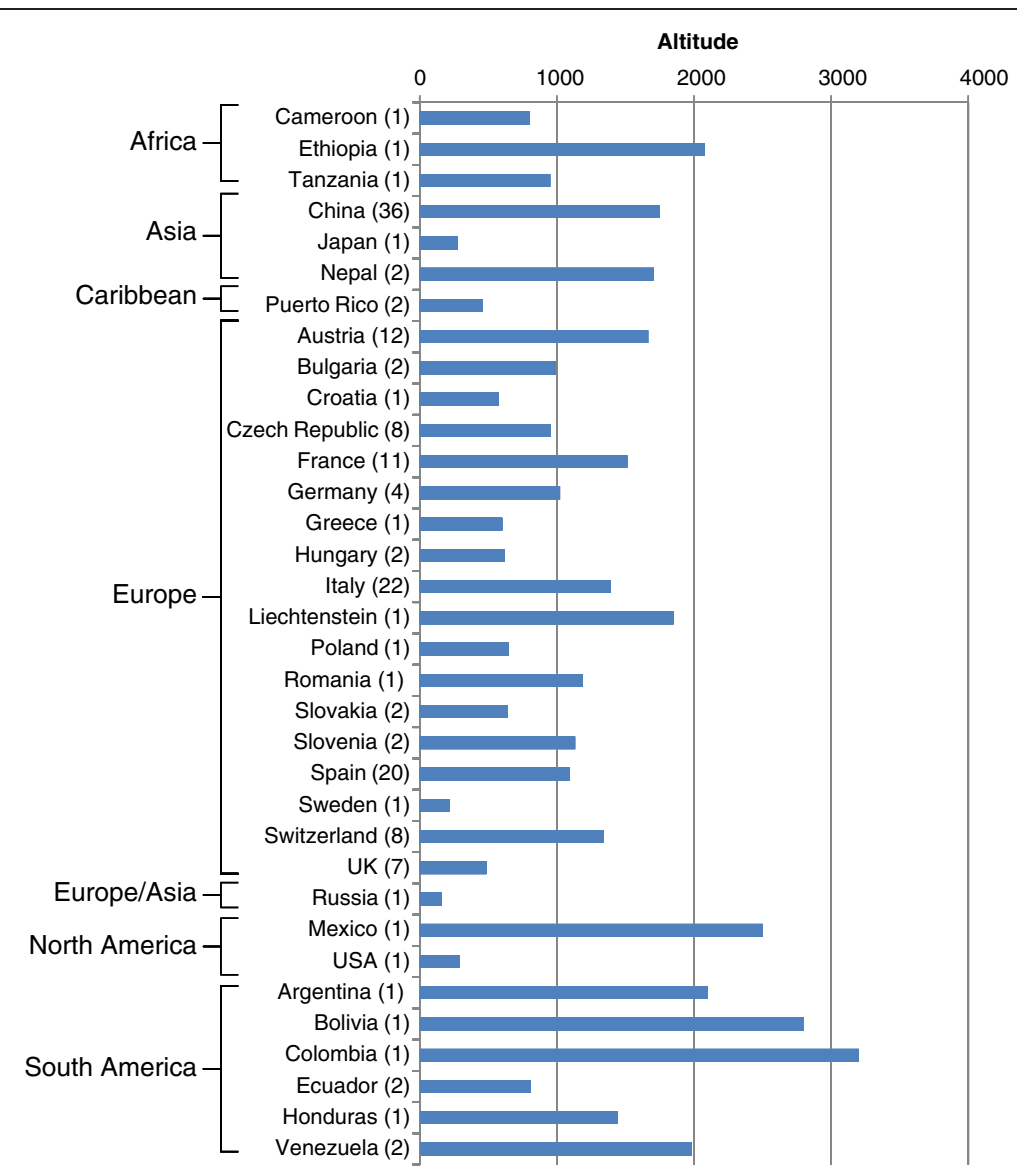

Figure 7 Mean reported study altitude per country for studies included in the systematic map. Numbers in brackets represent the number of studies reporting altitude for that country.

geographical concentration of research is likely to be driven by the availability of research funding and funded demand for knowledge in decision-making.

China and Spain are well-represented by studies reporting soil outcomes. Studies measuring soil outcomes are shown for these two countries in Figures 12 and 13 respectively. Whilst there is a geographical bias in both countries (in the Loess Hilly Plateau in China and the Aisa Valley in the Pyrenees in Spain), there is a moderate spread of a minority of studies across other areas.

\section{Discussion}

\section{Key findings}

The aim of this map is to document the available evidence on the topic of farmland abandonment in high altitude and mountainous regions, where topography adversely

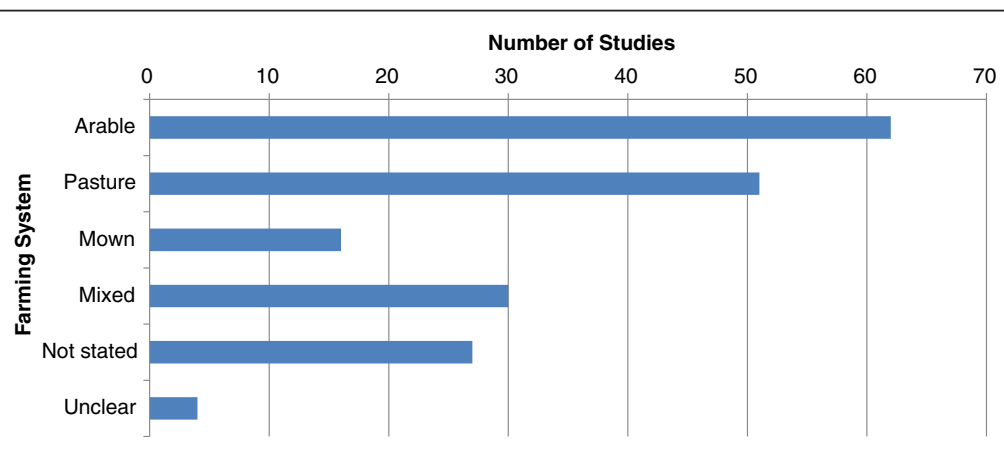

Figure 8 Farming systems investigated in included studies in the systematic map. 


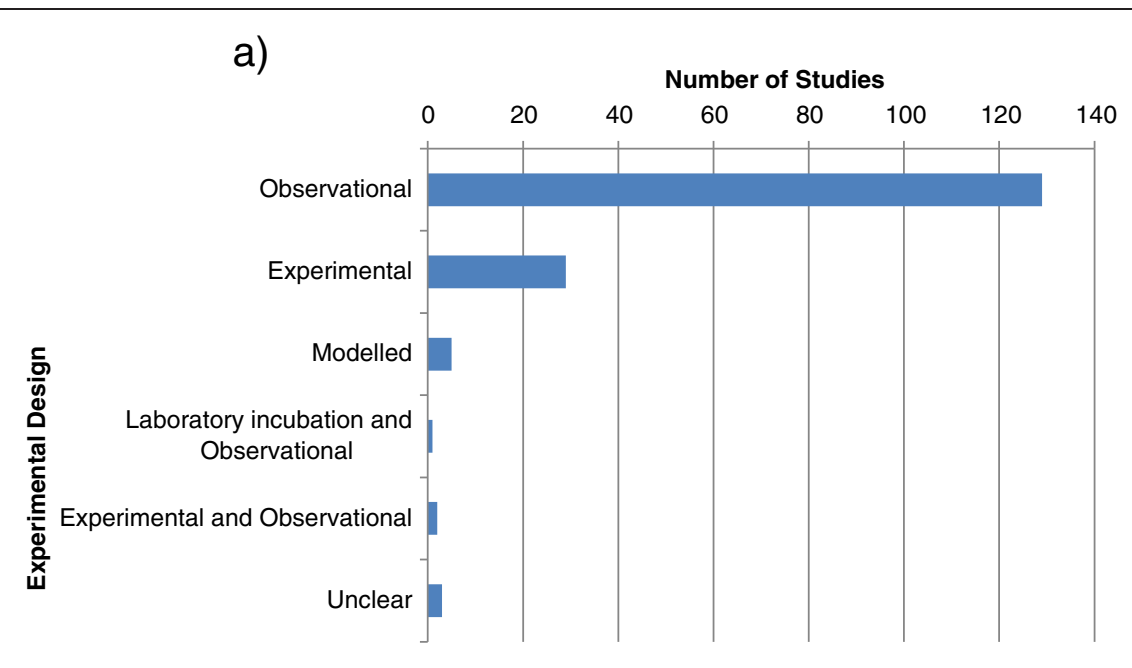

b)

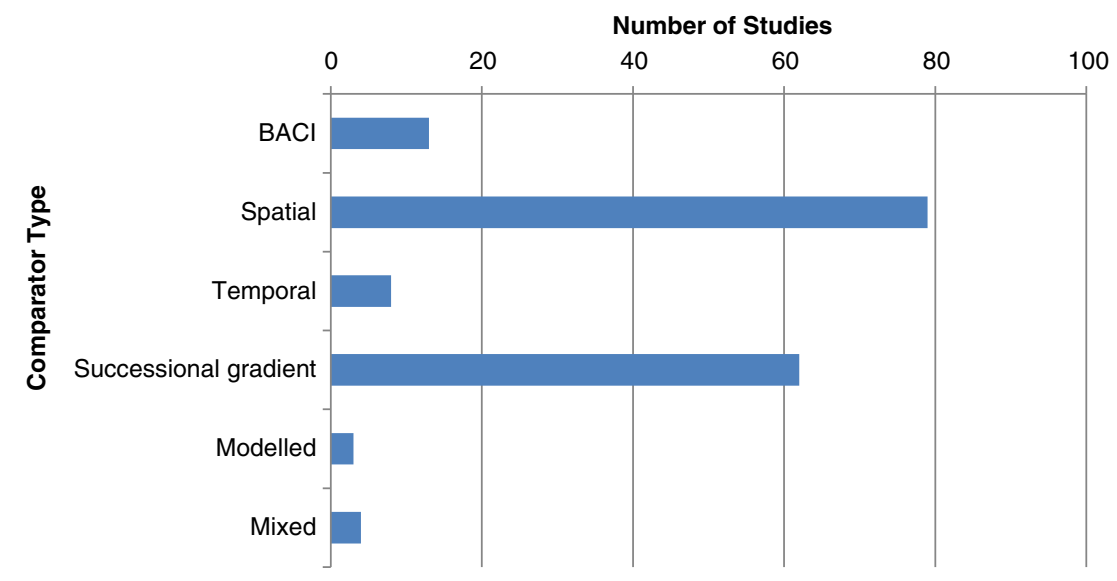

Figure 9 Study design (a) and comparator type (b) for included studies.

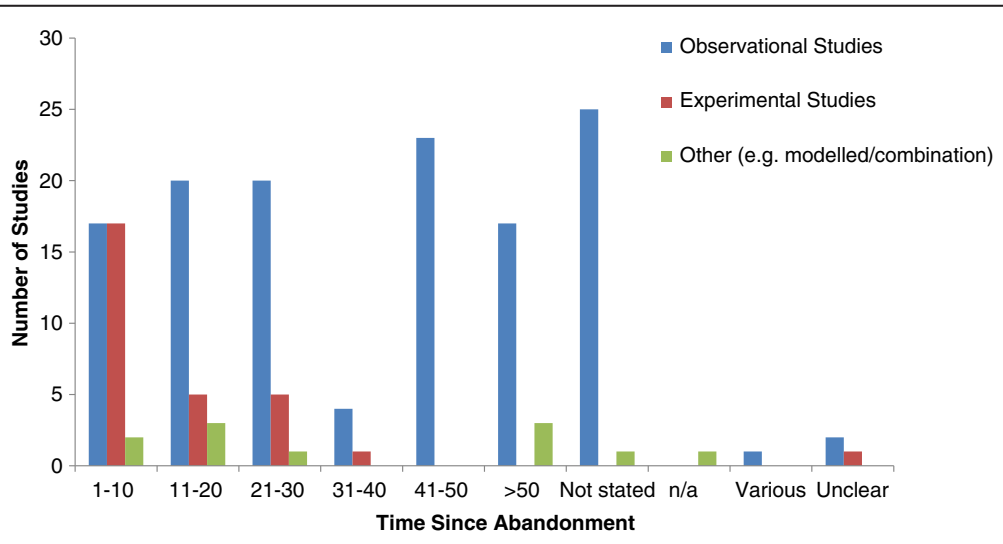

Figure 10 Time since abandonment (in years) of studies included in the systematic map, separated by study type. 


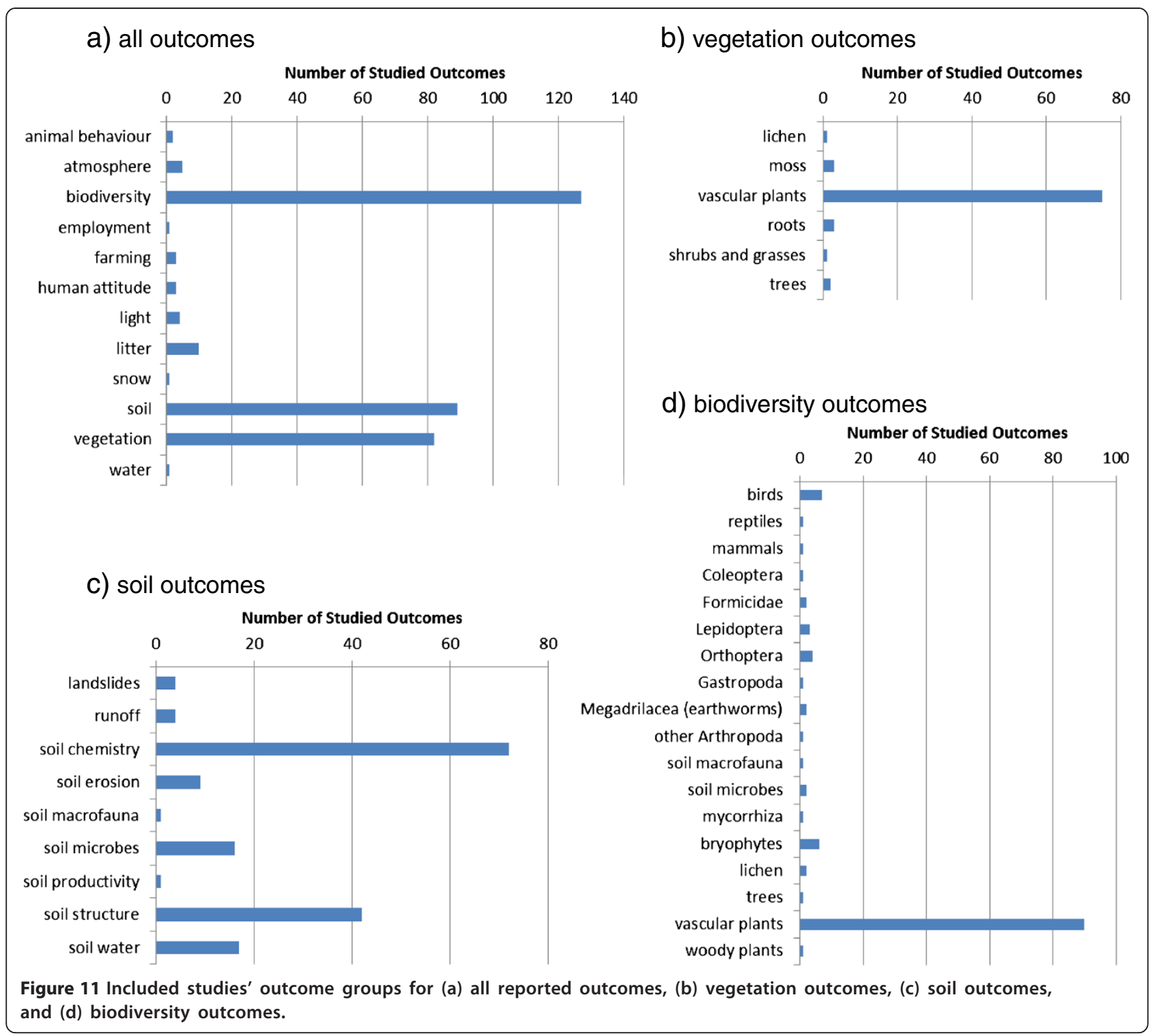

affects farming activities. We have identified a body of 185 articles describing 169 studies of agricultural abandonment. This abandonment spans various farming systems, 35 named countries and 12 major outcome groups. The volume and quality of the various subgroups of evidence (i.e. by country and outcome) vary greatly, and whilst some areas may be represented by high numbers of studies, the average quality of the evidence is not particularly high. There appear to be a number of regions that are well-studied, including the Aisa Valley in Spain and the Loess Plateau in China. Whilst these bodies of evidence may lend themselves well to further synthesis, they may be rather limited in terms of their generalisability because of their limited geographical extent.

\section{Limitations of the systematic map}

The following caveats should be highlighted when considering the outputs of this systematic map.

Descriptors of the topography of included studies vary significantly in the evidence base according to researchers and study countries. It is well-known that countries have different official definitions of 'mountainous regions', for example in European Union member states see [13]. We have aimed to include any study that identifies its study region as being high altitude, mountainous, or subject to steep topography using one of the synonyms identified during scoping. By including studies undertaken at high altitude, we have included plateaus in our map. Where these plateaus are extensive, topography may not adversely affect farming practices, and these systems may 


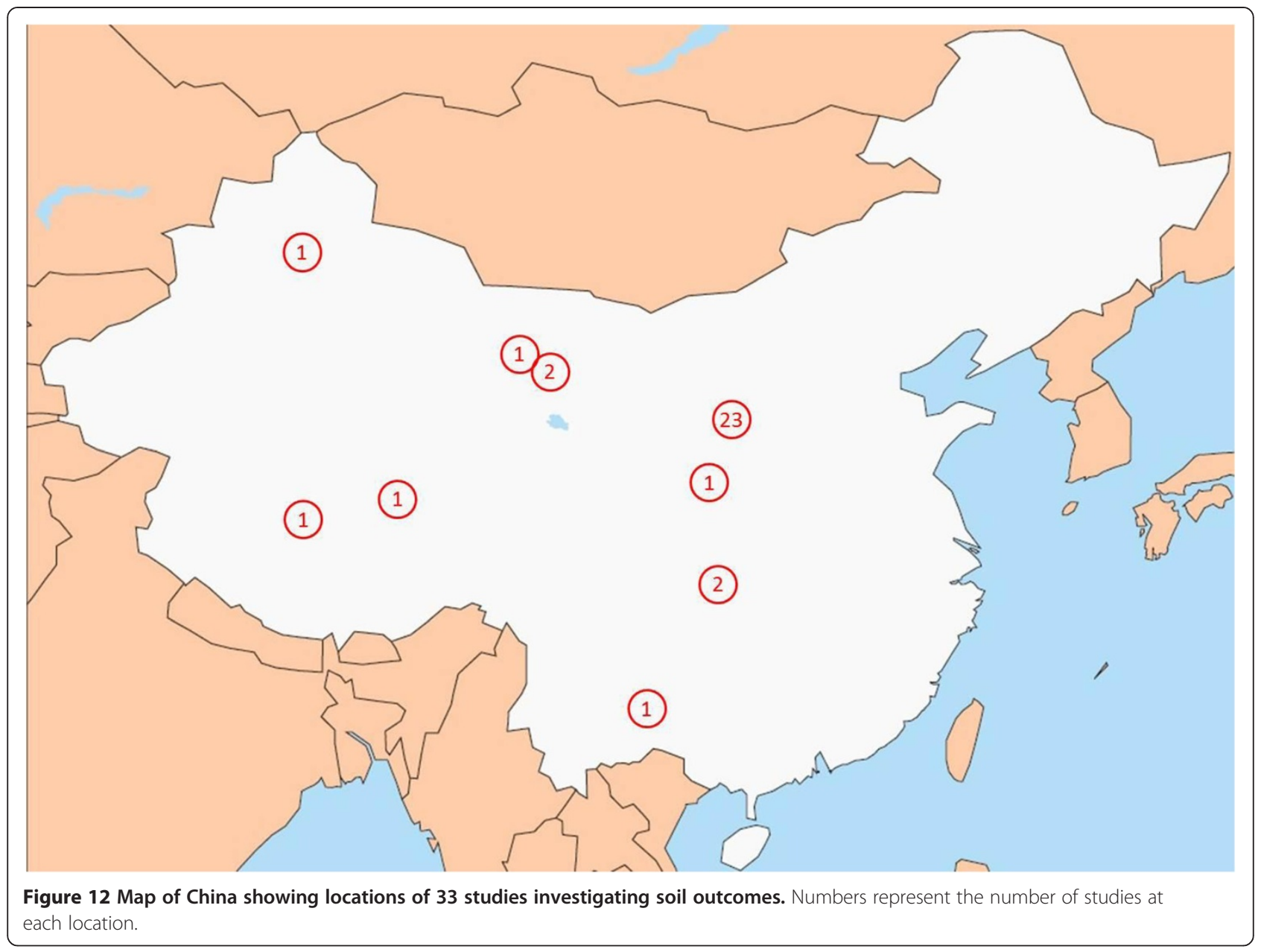

differ substantially in their causal pathways of abandonment to other high altitude or mountainous regions. This issue is almost exclusively restricted to studies undertaken on the Loess Plateau in China, although we may be overestimating the extent of the issue, since this is also sometimes referred to as the Loess Hilly Plateau. Local expert knowledge would be useful to differentiate between study sites that may and may not be influenced in their agricultural practices by topography.

During the review process we identified 4 descriptors that were not in our original string by iteratively populating a list of descriptors; cordillera, gradient, terrain and inclination. In addition, incline and topography were included in a post hoc test in Web of Knowledge (WoK). These 6 synonyms added 894 titles to the original 7,213 hits. Future updates to this map should consider including these additional terms in the search for novel evidence. Given a final inclusion rate of $1.9 \%$ relative to the WoK search results we might predict 17 of these articles could be pertinent to the review. To our knowledge this is the first review to employ such post-review synonym relevance assessment. We believe such analysis would be useful in all systematic reviews and systematic maps in both scoping (currently a common practice) and final reviews/maps. Whilst we performed an assessment of common synonyms during scoping, only a full assessment of the relevant evidence can allow such a complete analysis of synonym completeness.

There is a risk that this map may have failed to identify all of the available literature on the topic, since authors may not have included high altitude/mountain descriptors in their titles, abstracts or keywords. Seven articles were identified that did not contain high altitude/mountain descriptors in these sections but that were, nonetheless, undertaken at altitude. However, it would be unfeasible to screen search results for all abandonment literature in search of relevant high altitude/mountain region studies. This risk can be mitigated by consultation with experts to maximise the inclusion of relevant research, which was a key strength of this review.

Thirteen studies in non-English languages were included in the review (French, 1; Spanish, 1; German, 1; Chinese 10). Articles that could not be translated often appeared to be relevant but could not be clearly translated by the review 


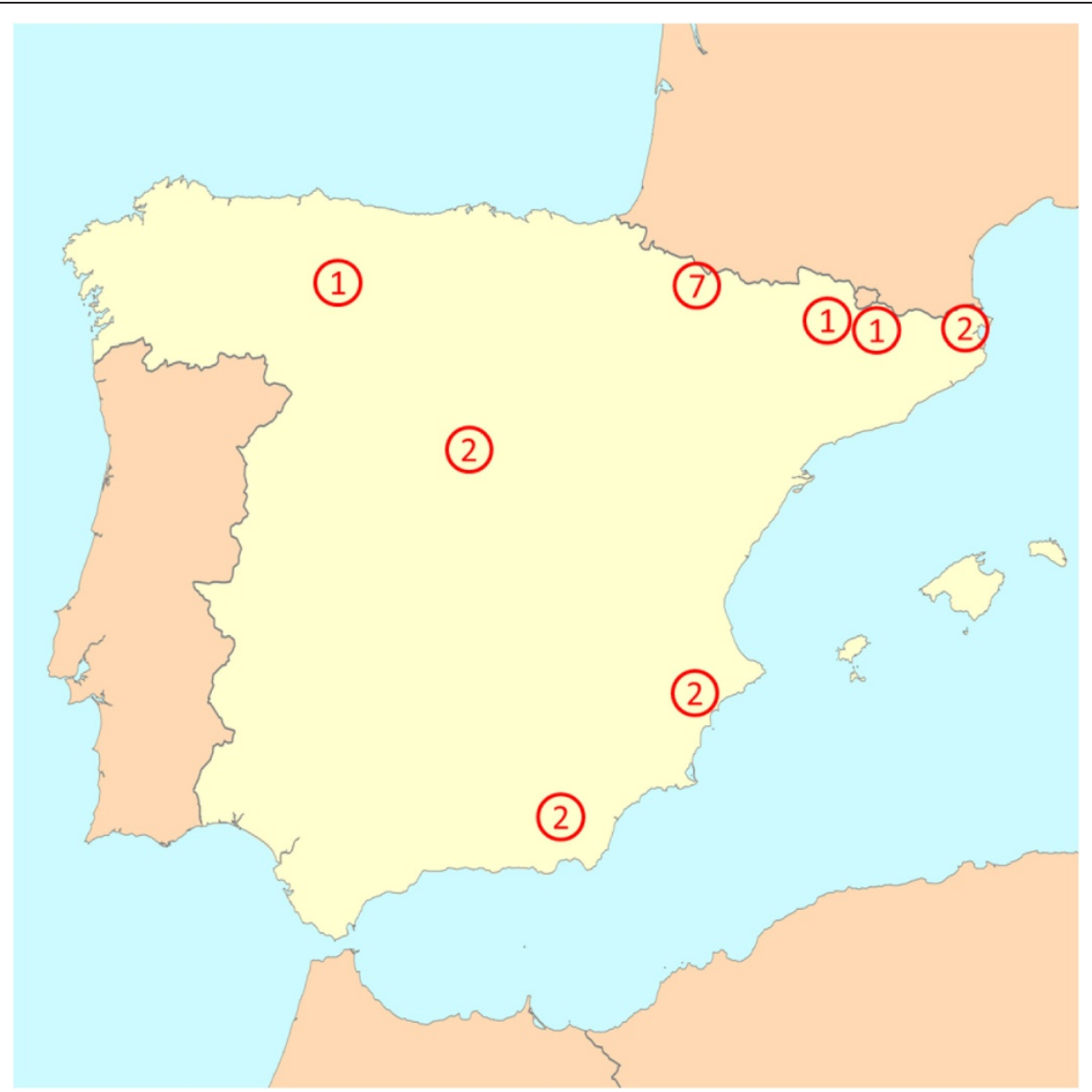

Figure 13 Map of Spain showing locations of 18 studies investigating soil outcomes. Numbers represent the number of studies at each location.

team in sufficient detail to assess the suitability of the comparator, details of the intervention, or the level of methodological detail. In particular, the presence of complete abandonment was difficult to assess. In addition, a number of articles could not be translated using automated translation tools due to restrictions on 'copy-and-paste' functions within digital articles. The ability to include these 26 untranslated articles would add strength to the accuracy of the map and any resultant syntheses.

Some studies examining experimental grazing exclusion were included in this map. These are pertinent to the review question, but they may only represent a small subset of the grazing exclusion literature. We believe that this may be the case since the term 'exclusion' was deliberately not included in our search string. However, some studies were identified as relevant through bibliographic searching. These studies simulated abandonment over a sufficient period for our inclusion criteria ( $>1$ year) but did not refer to abandonment or destocking within their titles, abstracts or keywords and would therefore not have been identified using our search string. Since these studies may only be a proportion of the available literature on experimental investigation of high altitude and mountain region grazing abandonment we recommend this subset of the literature (experimental, pasture categories) be treated with caution until it can be validated.

\section{Limitations of the evidence base}

The following aspects of the evidence base were highlighted during the systematic mapping process.

Many studies were not adequately replicated, with 72 scoring 0 for critical appraisal of replication (studies with 1 to 3 replicates per intervention/comparator group, or those that failed to report replication clearly). Articles were often unclear about the level of replication, and true replication was commonly difficult to discern from pseudoreplication (i.e. within-site sampling).

Few studies described the spatial scale of experiments in sufficient detail. Sample locations were not described, precluding an assessment of the contiguity of samples (i.e. whether closely located samples were pseudoreplicates or true replicates). Furthermore, this lack of detail 
makes assignment of scale to each study difficult; for example whether a study was undertaken at the plot, field or landscape scale.

One possibly common confounder that is unaccounted for in included studies in this map is the presence of extensive grazing on abandoned arable land. Several articles were excluded from the map due to the confounding effect of arable fields being abandoned and subsequently grazed extensively. This appears to be a relatively common practice in mountainous regions. However, this fully confounds any assessment of the impacts of farmland abandonment since comparator sites aren't equally grazed. Where stated, these studies were excluded, but there is a potential for this to be an undisclosed confounder, as several studies casually mentioned extensive grazing very briefly and sometimes outwith the methodology sections.

Very few studies reported their sample selection procedure. It is assumed that many of these studies selected samples purposefully, and are therefore open to sample selection bias. This may be of particular influence on the studies' findings where sample sizes were low. Twentyeight studies used random or exhaustive sampling, whilst a further 3 appeared to have used some form of randomisation. The remaining 138 studies used either purposive sampling or failed to report their sampling procedure.

\section{Implications for policy/practice}

Systematic maps aim to document and categorise all available evidence on a topic of interest. The outputs therefore represent a first step toward formalising the evidence base and decision makers may find the map useful in initial gauging of the extent of the evidence and extracting relevant evidence on more specific aspects of the subject (e.g. for questions of national or regional importance). The map should help identify cases where there may be sufficient data on a specific policy-relevant question to justify a systematic review and synthesis of effects (see section Implications for synthesis below).

\section{Implications for research \\ Implications for primary research}

This map identifies a number of understudied subtopics that may correspond to knowledge gaps, which could benefit from primary research. In addition, an assessment of susceptibility to bias (critical appraisal) identified areas that have been frequently studied but that typically do not have strong evidence: these areas should be supplemented with high quality research.

Knowledge gaps were identified in the following areas:

1. Africa, Asia (excluding China), North America and South America - all outcomes
2. Europe - natural hazards (fire hazard, avalanche risk and flood risk), socioeconomic outcomes, animal behaviour and atmosphere

3. Global - fire hazard, avalanche risk and flood risk

4. UK - vegetation and soil

5. Czech republic - soil

6. France - soil

7. Key mountain ranges - including the Rockies, the Andes, the Caucasus, the Himalaya, the Karakoram, the Great Dividing Range and the Urals

Frequently studied research areas that were judged to be highly susceptible to bias are as follows:

1. China - overall and for biodiversity, soil and vegetation

2. Italy - overall and vegetation

3. Spain - overall and soil

\section{Implications for synthesis}

This review highlights a number of subtopics within the evidence that would be suitable for systematic review. The following questions have suitable numbers of studies to permit synthesis in a full systematic review, although the latter two questions relate to evidence that, in general, has been coarsely coded as highly susceptible to bias:

1. What is the impact of farmland abandonment in high altitude/mountain regions on biodiversity and vegetation in Europe?

2. What is the impact of farmland abandonment in high altitude/mountain regions on biodiversity and vegetation in the European Alps?

3. What is the impact of farmland abandonment in high altitude/mountain regions on soil in Spain?

4. What is the impact of farmland abandonment on the Loess Plateau (China) on biodiversity, soil and vegetation?

The progression from studies within this map to full systematic review is a relatively small task, since the time-consuming stages of full systematic review (namely, searching, screening and full text assessment) have already been undertaken, and all that remains to be done for the above questions is full data extraction (partially completed within this map), full critical appraisal (including external validity assessment) and qualitative/quantitative synthesis where appropriate. In addition we strongly advise the inclusion of stakeholder engagement for these full review questions to ensure that relevant stakeholders are made aware of the synthesis and included in prioritisation and dissemination efforts. Furthermore, as always, this map should be updated to ensure new evidence is included, and calls for evidence pertinent 
to the review questions above should be made to maximise the likelihood of including all available evidence.

\section{Appendix}

How to search the systematic map database

To open the database

- Open the Access database file (.accdb) using Microsoft Access

- Open the Full Text Map table (double click) using the 'Tables' panel on the left

\section{To search for evidence}

1. Simple search - e.g. searching for studies undertaken in arable farming systems

- Navigate to the column titled 'Farming System' using the navigation bar or the right cursor

- Click the arrow in the right end of the column title

- Choose only the 'Arable' tick box

- Click OK

- The database will filter out only the Arable farming system studies

2. Multi-topic search - e.g. what research exists on arable farming from Switzerland?

- Proceed as above to filter out only arable farming studies

- Navigate to the 'Study Country/ies' column and select only 'Switzerland'

3. Searching for a term - e.g. bulk density

- Proceed to the relevant column

- Click the arrow in the right end of the column title

- Select 'Text Filters' > 'Contains'

- Enter search text and click OK

When finished filtering click the 'Filter' or 'Toggle Filter' buttons in the 'Home' tab to show the full database.

\section{Other included information}

- First author

- Email address

- Full reference

- Publication year

- Publication type

- Publication format

- Accessibility notes

- Study timing

- Study length

- Farming system (arable, mown, grazed)

- Altitude

- Experimental design

\section{Additional files}

Additional file 1: Search String Development and Database Search Strategy.

Additional file 2: Web Search Engine Search Strategy.

Additional file 3: Organisational Website Search Strategy.

Additional file 4: Bibliographic Checking Strategy.

Additional file 5: Author-submitted Evidence Received after Map

Completion.

Additional file 6: Unobtainable and Untranslated Articles.

Additional file 7: Excluded Articles at Full Text Screening.

Additional file 8: Coding Framework.

Additional file 9: Systematic Map (Microsoft Access and Excel versions [CA only in Excel]).

Additional file 10: Table S1. Major outcome groups within studies across different countries arranged by continent.

Additional file 11: Table S2. Evidence strength of studies across different countries arranged by continent.

Additional file 12: Table S3. Average evidence item strength across different countries arranged by continent.

\section{Competing interest}

The authors declare that they have no competing interest.

\section{Authors' contributions}

$\mathrm{NRH}$ managed and planned the conduct of the systematic map and undertook all mapping activities. ASP, DS, and NRH conceived and refined the map question. ASP and DS assisted in interpretation, synthesis and writing. All authors read and approved the final manuscript.

\section{Acknowledgements}

The authors thank the European Commission for funding this research. We also thank Nicola Randall from the CEE Systematic Mapping Methods Group for advice on systematic mapping practicalities.

Sources of support

This research is undertaken as part of a project funded by the European Commission's Joint Research Centre through Service Contract Number 153172-2012 A08 GB. All statements/comments within this document belong to the authors and do not necessarily represent the views of the European Commission.

\section{Author details}

${ }^{1}$ Centre for Evidence-Based Conservation, School of the Environment and Natural Resources and Geography, Bangor University, Bangor LL57 2UW, UK. ${ }^{2}$ School of the Environment and Natural Resources and Geography, Bangor University, Bangor LL57 2UW, UK.

Received: 17 February 2014 Accepted: 8 July 2014 Published: 13 August 2014

\section{References}

1. Pointereau P, Coulon F, Girard P, Lambotte M, Stuczynski T, Sanchez Ortega V, Del Rio A, Anguiano E, Bamps C, Terres J: Analysis of farmland abandonment and the extent and location of agricultural areas that are actually abandoned or are in risk to be abandoned. Ispra: European Commission-JRC-Institute for Environment and Sustainability; 2008.

2. MacDonald D, Crabtree J, Wiesinger G, Dax T, Stamou N, Fleury P, Gutierrez Lazpita J, Gibon A: Agricultural abandonment in mountain areas of Europe: environmental consequences and policy response. J Environ Manage 2000, 59:47-69.

3. Ramankutty N, Foley JA: Estimating historical changes in global land cover: Croplands from 1700 to 1992. Global Biogeochem Cycles 1999. 13:997-1027.

4. Hobbs RJ, Cramer VA: Why old fields? Socioeconomic and ecological causes and consequences of land abandonment. In Old Fields: Dynamics 
and Restoration of Abandoned Farmland. Edited by Cramer VA, Hobbs RJ. Washington DC: Island Press; 2007:1-14.

5. Schuler M, Stucki E, Roque O, Perlik M: Mountain Areas in Europe: Analysis of mountain areas in EU member states, acceding and other European countries. In Final report, January: Nordregio, Nordic Centre for Spatial Development, European Commission contract No 2002.CE.16.0.AT.136. 2004.

6. Körner C, Paulsen J, Spehn EM: A definition of mountains and their bioclimatic belts for global comparisons of biodiversity data. Alp Bot 2011, 121:73-78.

7. Baldock D, Beaufoy G, Brouwer F, Godeschalk F: Farming at the margins: abandonment or redeployment of agricultural land in Europe. London: Institute for European Environmental Policy The Hague; 1996.

8. Moravec J, Zemeckis R: Cross Compliance and Land Abandonment. In A research paper of the Cross-Compliance Network (Contract of the European Community's Sixth Framework Programme, SSPE-CT-2005-022727), Deliverable D17 of the Cross-Compliance Network. 2007.

9. Jodha NS: Mountain agriculture: the search for sustainability. J Farm Syst Res Ext 1990, 1:55-75.

10. Rey Benayas J, Martins A, Nicolau JM, Schulz JJ: Abandonment of agricultural land: an overview of drivers and consequences. $C A B \operatorname{Rev}$ Perspect Agric Vet Sci Nutr Nat Resour 2007, 2:1-14.

11. Plieninger $T$, Gaertner $M$, Hui $C$, Huntsinger L: Does land abandonment decrease species richness and abundance of plants and animals in Mediterranean pastures, arable lands and permanent croplands? Environ Evid 2013, 2:1-7.

12. Coppola A: An economic perspective on land abandonment processes. In Working paper n. 1/2004. presented at the AVEC Workshop on "Effects of Land Abandonment and Global Change on Plant and Animal Communities. Anacapri, October 11-13, 2004. 2004.

13. Haddaway NR, Styles D, Pullin AP: Environmental impacts of farm land abandonment in high altitude/mountain regions: a systematic map of the evidence. Environ Evid 2013, 2:18.

14. Cohen J: A coefficient of agreement for nominal scales. Educ Psychol Meas 1960, 20:37-46.

doi:10.1186/2047-2382-3-17

Cite this article as: Haddaway et al.: Evidence on the environmental impacts of farm land abandonment in high altitude/mountain regions: a systematic map. Environmental Evidence 2014 3:17.

\section{Submit your next manuscript to BioMed Central and take full advantage of:}

- Convenient online submission

- Thorough peer review

- No space constraints or color figure charges

- Immediate publication on acceptance

- Inclusion in PubMed, CAS, Scopus and Google Scholar

- Research which is freely available for redistribution 